STUDI

FRANCESI

\section{Studi Francesi}

Rivista quadrimestrale fondata da Franco Simone

142 (XLVIII | I) | 2004

Varia - fasc. I - gannio-aprile 2004

\title{
Une Expérience rhétorique. L'éloquence de la Révolution, Textes réunis par Eric Négrel et Jean-Paul Sermain
}

\section{Regina Bochenek-Franczakowa}

\section{(2) OpenEdition}

1 Journals

\section{Édition électronique}

URL : https://journals.openedition.org/studifrancesi/40722

DOI : $10.4000 /$ studifrancesi. 40722

ISSN : 2421-5856

Éditeur

Rosenberg \& Sellier

\section{Édition imprimée}

Date de publication : 1 juillet 2004

Pagination : 194-195

ISSN : 0039-2944

\section{Référence électronique}

Regina Bochenek-Franczakowa, « Une Expérience rhétorique. L'éloquence de la Révolution, Textes réunis par Eric Négrel et Jean-Paul Sermain », Studi Francesi [En ligne], 142 (XLVIII | I) | 2004, mis en ligne le 30 novembre 2015, consulté le 09 septembre 2021. URL : http://journals.openedition.org/ studifrancesi/40722 ; DOI : https://doi.org/10.4000/studifrancesi.40722

Ce document a été généré automatiquement le 9 septembre 2021.

\section{(c) $(1) \odot$}

Studi Francesi è distribuita con Licenza Creative Commons Attribuzione - Non commerciale - Non opere derivate 4.0 Internazionale. 


\title{
Une Expérience rhétorique. L'éloquence de la Révolution, Textes réunis par Eric Négrel et Jean-Paul Sermain
}

\author{
Regina Bochenek-Franczakowa
}

\section{RÉFÉRENCE}

Une Expérience rhétorique. L'éloquence de la Révolution, Textes réunis par Eric NÉGREL et Jean-Paul SERMAIN, Oxford Voltaire Foundation, SVEC 2002:02, pp. 333.

1 Il est généralement admis que la Révolution constitue un moment historique unique pour la parole publique; en même temps, «de ce continent neuf, bien peu de cartes ont été tracées» (p. 1). Dans l'optique de l'ensemble de ce volume, il s'agit d'examiner le phénomène dans ses contradictions: ne pas s'arrêter à la dénégation de la rhétorique sous la Révolution, mais comprendre ce qui s'est inventé et les problèmes qui se sont posés (p. 8). Le volume se compose de trois parties. La première («Modes oratoires») contient des études des cas particuliers mais à la fois typiques de l'éloquence révolutionnaire: Aurelio PRINCIPATO (Comment restituer l'action oratoire de la Révolution? pp. 19-33) soulève le problème l'actio des discours révolutionnaires, les traces laissées dans les témoignages, les textes eux-mêmes, les traités, etc. ne suffisant pas toujours à en restituer les aspects véritables. Pour Peter FRANCE («A Tale of two cities»: l'éloquence à Westminster et à Paris, pp. 35-44) la comparaison entre l'éloquence de l'Assemblée nationale et celle de la Chambre des Communes est instructive, vu que le parlement anglais était un modèle pour les révolutionnaires français. Sylviane LEONI se penche sur les discours de Saint-Just pour dégager ce qui constitue leur fameux «laconisme» (Laconisme et lieux communs dans les discours de Saint-Just, pp. 45-54). Les discours d'autres grands orateurs révolutionnaires, aussi bien montagnards que girondistes, sont examinés par Peter KRAUSE- TASTET en rapport avec les modèles de la rhétorique antique (L'antiquité exemplaire: imitation et émulation dans les discours révolutionnaires, pp. 55-64). 
Isabelle MARTIN trace le portrait d'un curé de province hostile à la Révolution, dont les discours donnent l'exemple de l'éloquence dite populaire (Yves-Michel Marchais: l'éloquence de la chaire, de la critique à l'indignation, pp. 65-72). Sonia BRANCA-ROSOFF examine deux discours dans les débats de l'Assemblée où se sont affrontés des partis adverses: bon exemple pour montrer deux modèles d'argumentation et la force des figures rhétoriques (À propos d'un affrontement entre Maury et Clermont-Tonnerre: peut-on parler de deux modèles de rhétorique politique?, pp. 73-87). L'éloquence révolutionnaire c'est aussi l'empire de l'émotion: Sophie WAHNich l'étudie sur l'exemple de l'énoncé «la patrie est en danger» en 1792 (L'émotion en partage: l'Assemblée législative face aux dangers de la patrie (juin 1792), pp. 89-101). Les études composant la II ${ }^{\mathrm{e}}$ partie («Diffractions de l'éloquence») portent sur des cas divers de la rhétorique révolutionnaire. Hans-Jürgen LUSEBRINK présente et analyse un ouvrage qui joint le récit de la Révolution et le tableau de ses moments cruciaux (Gestes oratoires et représentations iconographiques: transcriptions de l'oralité dans les "Tableaux historiques de la révolution française», pp. 105-120). La chanson est un genre des plus importants de la Révolution: Herbert SCHNEIDER en étudie la rhétorique sur l'exemple d'un chansonnier des jacobins (La rhétorique de la chanson révolutionnaire: le cas $d u$ "Chansonnier de la Montagne», pp. 121-146). Un autre genre dominant: le théâtre est examiné dans ce qui le rapproche du genre épidictique (Eric NEGREL, Le théâtre au service de la Révolution: une rhétorique de l'éloge, pp. 147-164). Maria GIESCHE caractérise deux œuvres de compositeurs représentants du néo-classicisme persistant jusqu'à la fin de l'Empire (La rhétorique musicale du classicisme: l'antagonisme de Cherubini et de Spontini comme représentants de la Révolution française et de l'Empire, pp. 165-180). Tatiana SMOLiarova s'intéresse au phénomène de la rhétorique du comportement qui accompagne celle de l'œuvre, dans le cas de Le Brun-Pindare (Le rôle de la Révolution dans le destin du nom propre: le cas d'Ecouchard Le Brun, dit Le Brun-Pindare, pp. 181-190). Deux études sont consacrées à la présence des discours révolutionnaires en Allemagne (Annette KEILHAUER, L'éloquence révolutionnaire en allemand: Robespierre traduit, pp. 191-208 et Ingrid WEBER, «Die Revolution ist die Revolution»: George Foster observateur-propagateur de la révolution française, pp. 209-218). La III ${ }^{\mathrm{e}}$ partie («Réflexions théoriques») apporte des considérations plus générales sur le problème. Pour préciser ce qu'il faut entendre par le «moment rhétorique» spécifique de la Révolution, il s'avère intéressant de considérer le cas de Sieyès dont les discours combinent une rhétorique métaphysique et une éloquence pratique (Jacques GUILHAUMOU, La rhétorique des porte-parole (1789-1792): le cas Sieyès, pp. 221-229). Le statut de la rhétorique dans les Ecoles centrales est au centre d'intérêt de Brigitte SCHLIEBEN-LANGE et Jochen HAFNER (Rhétorique et Grammaire générale dans les Ecoles centrales, pp. 231-244). Les A. organisent leur réflexion autour de trois questions: pourquoi voulait-on faire disparaître la rhétorique de l'enseignement? comment cela se reflète dans l'organisation des Écoles? enfin, comment ce «non-lieu» fut rempli? Jean-Paul SERMAIN analyse les positions de La Harpe lequel s'engage dans la défense d'une conception antijacobine de la langue politique («Les formes ont ici une valeur»: la position singulière de La Harpe, pp. 245-255). Le même auteur se penche aussi sur un traité de rhétorique paru à la fin du siècle, exemple curieux et unique d'un texte théorique d'éloquence révolutionnaire (Une rhétorique républicaine: l'«Essai sur l'art oratoire» de Joseph Droz (1799), pp. 257-268). Dans les études qui ferment le volume, l'on pénètre déjà au siècle suivant: Patrick BRASART présente les idées de Mme de Staël sur l'éloquence révolutionnaire dont elle déplore la dégaradation finale (Les rendez-vous manqués: Mme de Staël et l'éloquence révolutionnaire, 
pp. 269-276). Maïté BouYssy présente un cas des plus intéressants: le fameux «Anacréon de la guillotine», Bertrand Barère, qui dans ses écrits de vieillesse fait preuve d'impuissance à se saisir lui-même dans l'Histoire (Bertrand Barère ou l'impossible fuite dans l'encre, pp. 277-296). Anne VIBERT passe en revue les étapes du développement de l'éloquence parlementaire en France tout au long du XIXe siècle, toujours en référence à celle de la Révolution (L'éloquence révolutionnaire: modèle ou contre-modèle pour l'éloquence politique au dix-neuvième siècle?, pp. 297-311).

2 Le mérite des études contenues dans ce volume n'est pas seulement d'apporter des analyses et aperçus nouveaux; l'on y trouve aussi une mine de renseignements précis: annexes, bibliographies, sources iconographiques. Enfin, les auteurs indiquent ce qui reste à faire pour explorer ce terrain toujours mal connu: les éditions des textes des discours, l'étude de l'enseignement de la rhétorique depuis 1766 ainsi que de l'intégration progressive de l'expérience de l'éloquence révolutionnaire dans la conscience collective des Français (p. 15).

De «ce continent neuf», il reste donc encore bien des «cartes à tracer». 